\title{
Effect of ACK on the Performance of Zigbee Topologies
}

\author{
Ahmed I. Al-Ghannam \\ Assistant teacher \\ Department of Electrical Engineering \\ Mosul University
}

\begin{abstract}
It's important in a Zigbee networking, how the Zigbee devices are communicate with each other in the network. In IEEE802.4 standard define three way to communicating the Zigbee devices with each other which are known as network topologies. The network topologies that define in this standard are star, Mesh and Tree topology. This paper focus on the performance of the Zigbee topologies depending on the measuring of the throughput, delay and the number of packets send and received. Many scenarios have been created in Opnet modeler simulation program to study the performance of the three network topologies (star, Mesh, and Tree). Finally to take the effect of activation of ACK mechanism in consideration, duplicate scenario for each network topology was configured with same network configuration and activation the ACK mechanism.
\end{abstract}

\section{Keywords}

Zigbee topologies, IEEE802.4 standard, Star, Mesh, Tree, ACK, Throughput, Delay.

\section{INTRODUCTION}

Zigbee networking today become used in many modern applications like internet of thing, healthcare, tracking and security system [1]. Zigbee based on wireless devices operate in $868 \mathrm{MHz}, 915 \mathrm{MHz}$, and $2.4 \mathrm{GHz}$ radio frequency bands. The maximum data rate is $250 \mathrm{~K}$ bits per second. This data rate consider low data rate. Zigbee is designed mainly for application need low data rate, low cost and long battery life [2]. In Zigbee networking there are two types of Zigbee devices that defines in IEEE802.4 standard. The first is the full function device (FFD) while the second is the reduce function device (RFD). The FFD devices are capable of performing all the duties that described in IEEE802.4 standard and accept any role in network while the RFD devices have processing power and memory size are normally less than of FFD devices and for this the RFD devices used in very simple applications [3]. The FFD devices in an IEEE802.4 network can take three roles: Coordinator, Router and End device. The coordinator and the Router are FFD devices [4]. The Coordinator able to initiate, terminate and relaying the data throughout the network while the Router is capable to relaying data throughout network only [5]. The End device may be FFD or RFD device. If the end device is an FFD device it can capable to relaying data. On the other hand, if the end device is an RFD device it cannot capable to relaying data and received data only [6]. The Zigbee network have an optional ACK, It is a technique that is optionally used in Zigbee networking to add the reliability to transmission process. The transmitter requests ACK when it is transmitting the packet to receive side then the receiver will send ACK to notify the transmitter that receiving is done [7].

\section{ZIGBEE TOPOLOGIES}

There are two main network topologies in Zigbee. The first is the star topology while the second is the peer to peer topology. In the star topology as shown in figure 1, the Zigbee devices (router, end device) can communicate only with the coordinator. In other words, any Zigbee device can't communicate direct with other this mean the Zigbee devices first sent the data to the coordinator and the coordinator relay the data to the other Zigbee devices (destinations) [8].

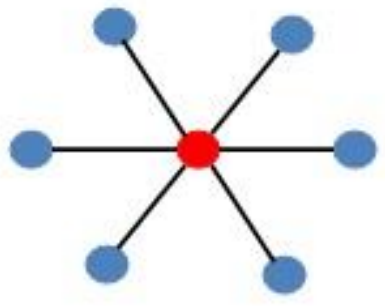

\section{Coordinator \\ End device}

Fig 1: star network topology

In a peer to peer topology as shown in figure 2, every Zigbee device can communicate directly with any other Zigbee device if this devices in the same coverage area of the radio wave. Any Zigbee device (FFD) in this topology can play the role of the coordinator. Depending on restrictions on the Zigbee device that communicate with each other the peer to peer topology can take different shapes. If there are no restrictions, the peer to peer topology is known as a mesh topology [9]. While another form of peer to peer topology is known as a Tree topology. In the Tree topology the coordinator establishes the initial network. Zigbee Routers form as branches and relay the data while the Zigbee end device act as leaves of the tree that it not participate in data relaying [9].

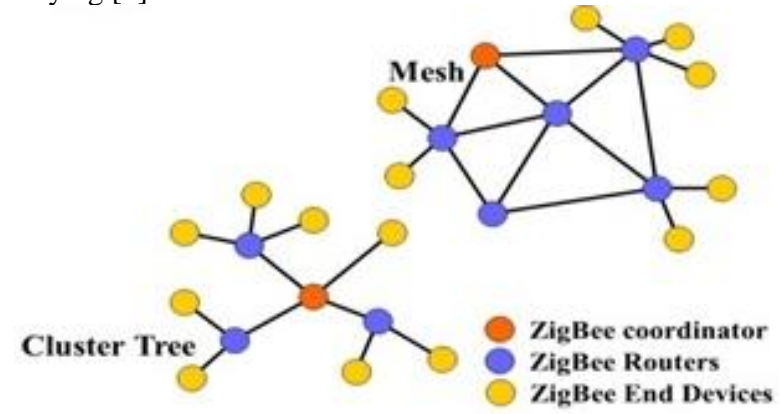

Fig 2: peer to peer (Mesh, Tree) topologies

\section{SIMULATION DESIGN AND RESULT ANALYSIS}

Many scenarios have been created in Opnet modeler simulation program to study the performance of the three 
Zigbee topologies (star, Mesh, and Tree). The main network parameters are shown in the table 1, It appear from the table that the packet destination is random to show all possible destinations of packet in the three topologies because the coverage area of the network nodes are overlapping.

Table 1: Network parameters that use in simulation

\begin{tabular}{|c|c|c|c|}
\hline & \multicolumn{3}{|c|}{ Zigbee topology } \\
\cline { 2 - 4 } & Star & Mesh & Tree \\
\hline $\begin{array}{c}\text { Maximum No. } \\
\text { Coordinator }\end{array}$ & 1 & 1 & 1 \\
\hline $\begin{array}{c}\text { Maximum No. } \\
\text { Children }\end{array}$ & 10 & 10 & 10 \\
\hline $\begin{array}{c}\text { Maximum No. } \\
\text { Routers }\end{array}$ & 0 & 4 & 4 \\
\hline $\begin{array}{c}\text { Maximum } \\
\text { depth }\end{array}$ & 1 & 4 & 4 \\
\hline $\begin{array}{c}\text { Packet } \\
\text { destination }\end{array}$ & random & random & Random \\
\hline $\begin{array}{c}\text { Packet } \\
\text { interarrival } \\
\text { time }\end{array}$ & $\begin{array}{c}\text { Constant } \\
(1.0)\end{array}$ & $\begin{array}{c}\text { Constant } \\
(1.0)\end{array}$ & $\begin{array}{c}\text { Constant } \\
(1.0)\end{array}$ \\
\hline $\begin{array}{c}\text { Packet size } \\
\text { Constant }\end{array}$ & $\begin{array}{c}\text { Constant } \\
(1024)\end{array}$ & $\begin{array}{c}\text { Constant } \\
(1024)\end{array}$ \\
\hline $\begin{array}{c}\text { Transmission } \\
\text { bands }\end{array}$ & $\mathbf{2 . 4 ~ G H z}$ & 2.4 GHz & $\mathbf{2 . 4 ~ G H z}$ \\
\hline $\begin{array}{c}\text { ACK wait } \\
\text { duration } \\
\text { (second) }\end{array}$ & $\mathbf{0 . 0 5}$ & $\mathbf{0 . 0 5}$ & $\mathbf{0 . 0 5}$ \\
\hline $\begin{array}{c}\text { Number of } \\
\text { retransmission }\end{array}$ & 5 & 5 & 5 \\
\hline
\end{tabular}

In scenario one as shown in figure 3, star Zigbee topology was configured with one coordinator and ten end devices that represent as network sensors. The end device can only communicate between them through the coordinator.

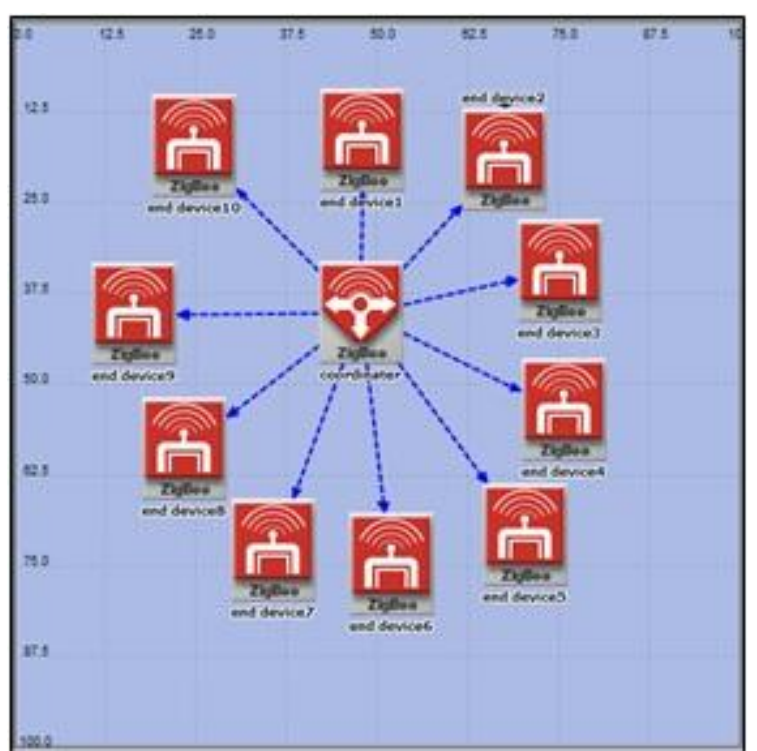

Fig 3: Star topology

While in scenario two as shown in figure 4, Mesh Zigbee topology was configured with one coordinator, four routers and ten end devices that represent as network sensors. Where the coordinator communicant with routers and end devices without any restriction and the end devices in this topology may be communicate direct with them.

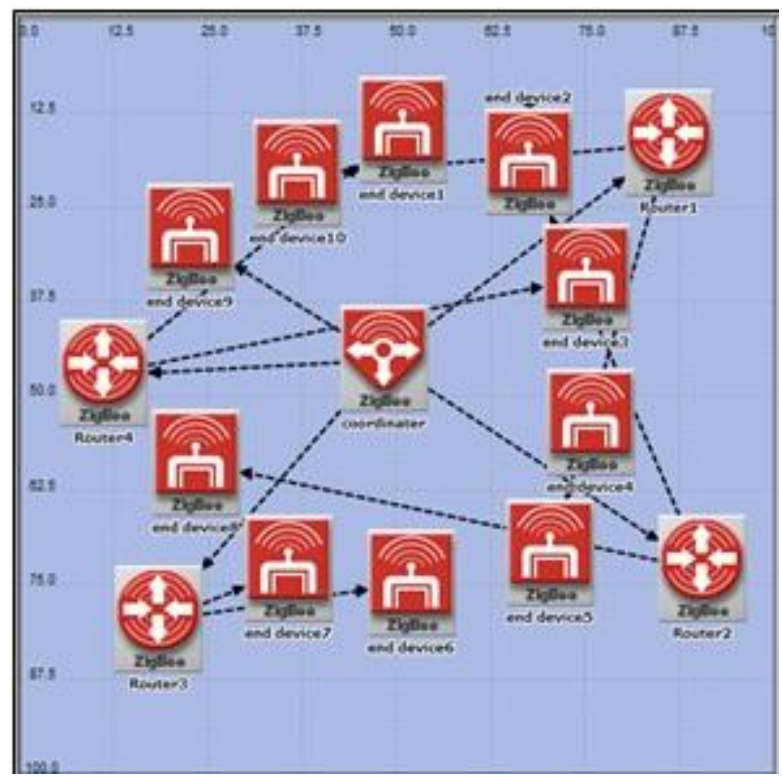

Fig 4: Mesh topology

Finally, in scenario three as shown in figure 5, Tree Zigbee topology was configured with one coordinator, four routers and ten end devices that represent as network sensors. In this topology the coordinator communicates with the parents and the parents itself communicate with your children.

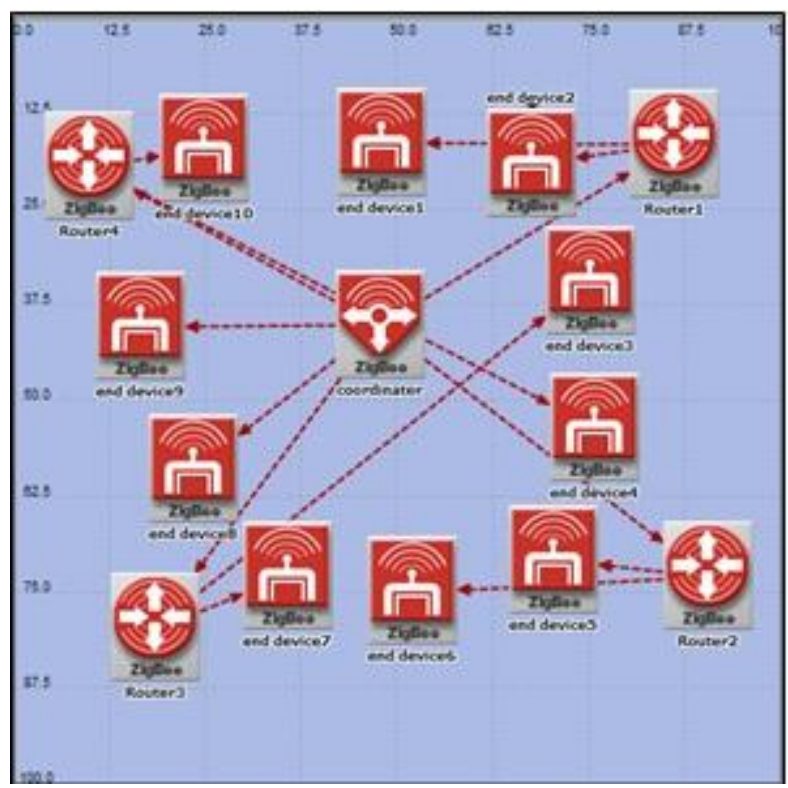

Fig 5: Tree topology

To take the effect of the optional ACK in consideration, duplicate scenario for each network topology was configured with same network configuration and activation the ACK mechanism.

From the results of packets sent (bits/sec) in MAC layer for the three network topologies (star, Mesh, Tree) as shown in figure 6, The Tree topology in general sent packet more than Mesh and Star topologies because in the star topology the all end devices communicate only through the coordinator to communicate between them while in the Mesh topology the packet send depending on the routing algorithm and the 
packet sent through different paths, In contrast the Tree topology more efficient to send packet hierarchy from coordinator to parents and finally to children.

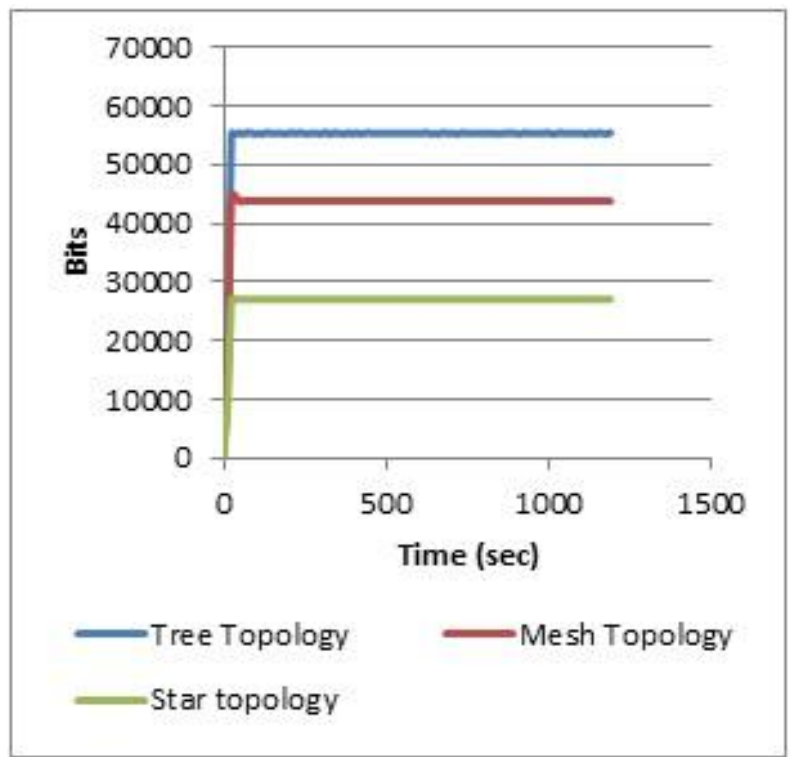

Fig 6: Traffic sent (bits/sec) for the Three network topology

The figure 7 shown the packet receive (bits/sec) in MAC layer for the three topologies by all destinations in the network that is possible to receive the packets.

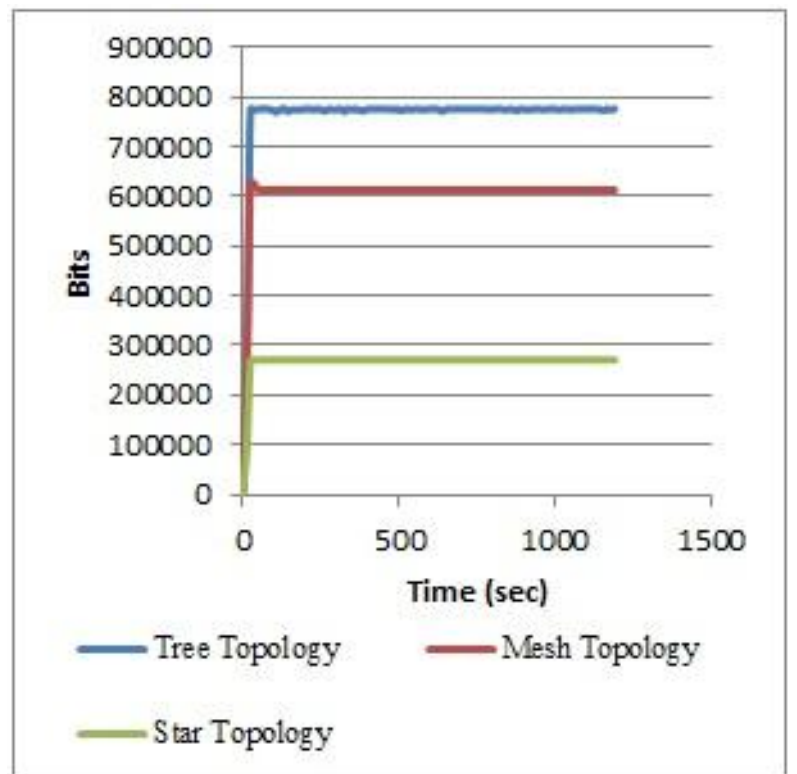

Fig 7: Traffic received (bits/sec) for the Three network topology

The figure 8 shown the throughput (bits/sec) in MAC layer,

Where the throughput in the Tree topology is the highest and is the lowest in star topology.

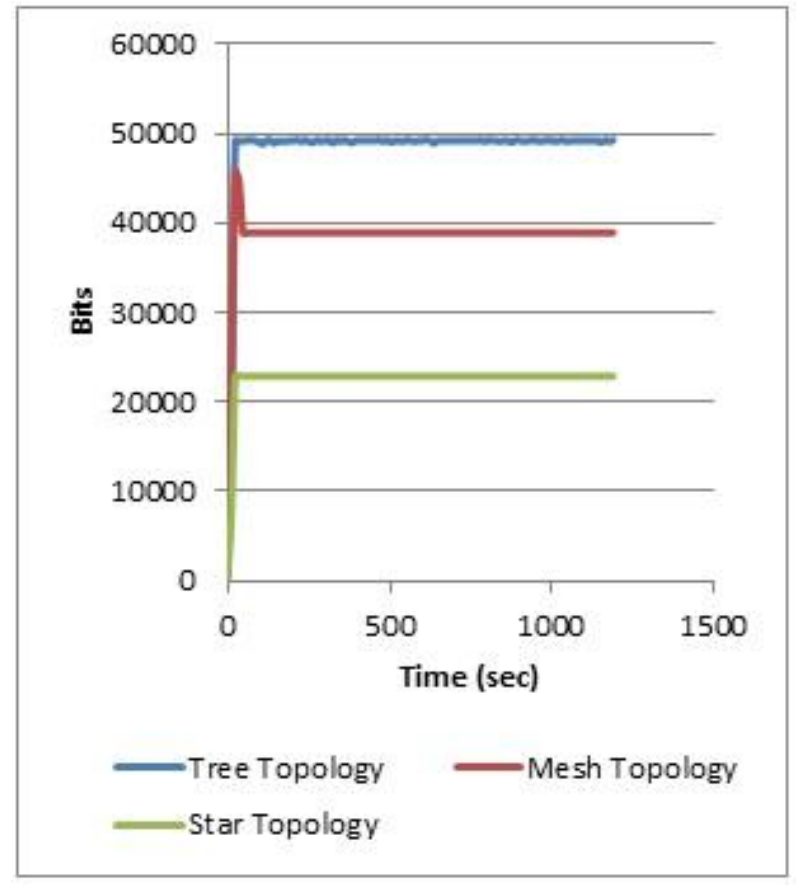

Fig 8: The throughput (bits/sec) for the three network topology

The end to end delay (sec) is shown in figure 9 for the three Zigbee topologies. This delay represents the total delay between creation and reception of an application packet. Where the star topology has less delay compare with Tree and Mesh topologies because in Tree and Mesh topologies the packet reach the destination by multi hops.

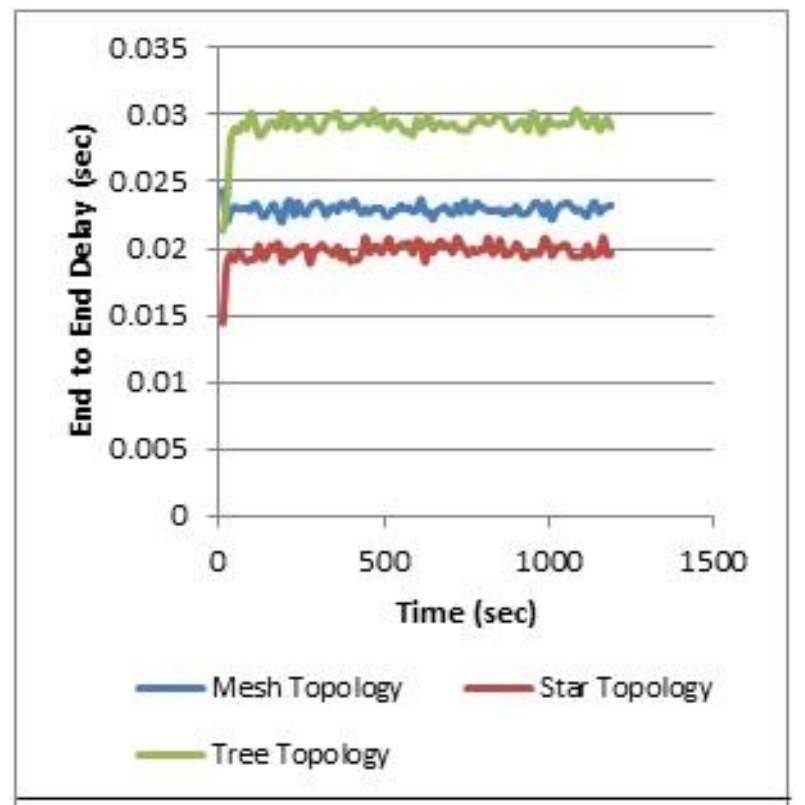

Fig 9: End to End delay (sec) for the three network topologies

When the ACK mechanism is active, the sending side don't send the next packet until received the ACK for the previous packet, this add more delay before sending new packets and in the same time reduce the number of packets that send as compared with the case of non-activation the ACK mechanism. The figure 10 shown the throughput (bits/sec) 
before and after activation ACK mechanism for the three topology, where the star topology effect more than Tree and mesh topology because the end devices only communicate through the coordinator and this may be causes an increase in packet collision. While the figure 11 shown the end to end delay $(\mathrm{sec})$.

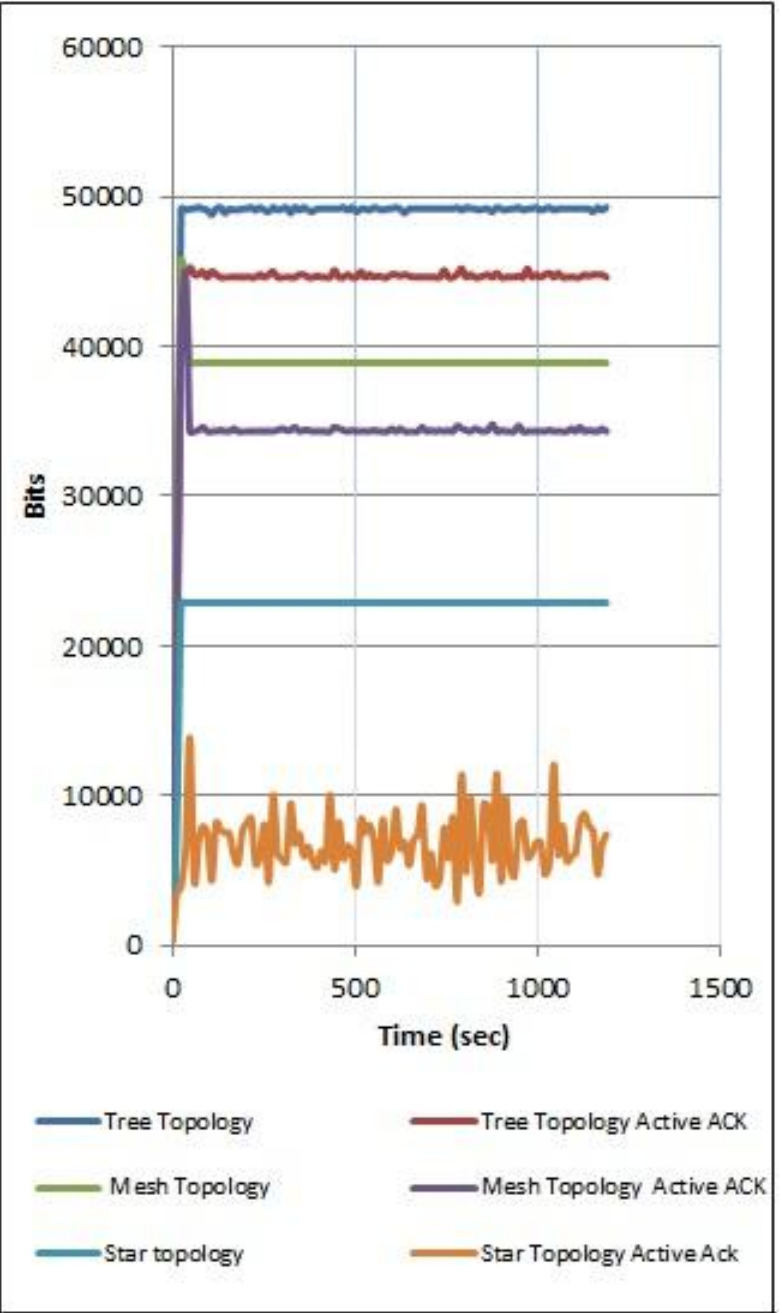

Fig 10: The throughput (bits/sec) for the three network topologies before and after activation of ACK.

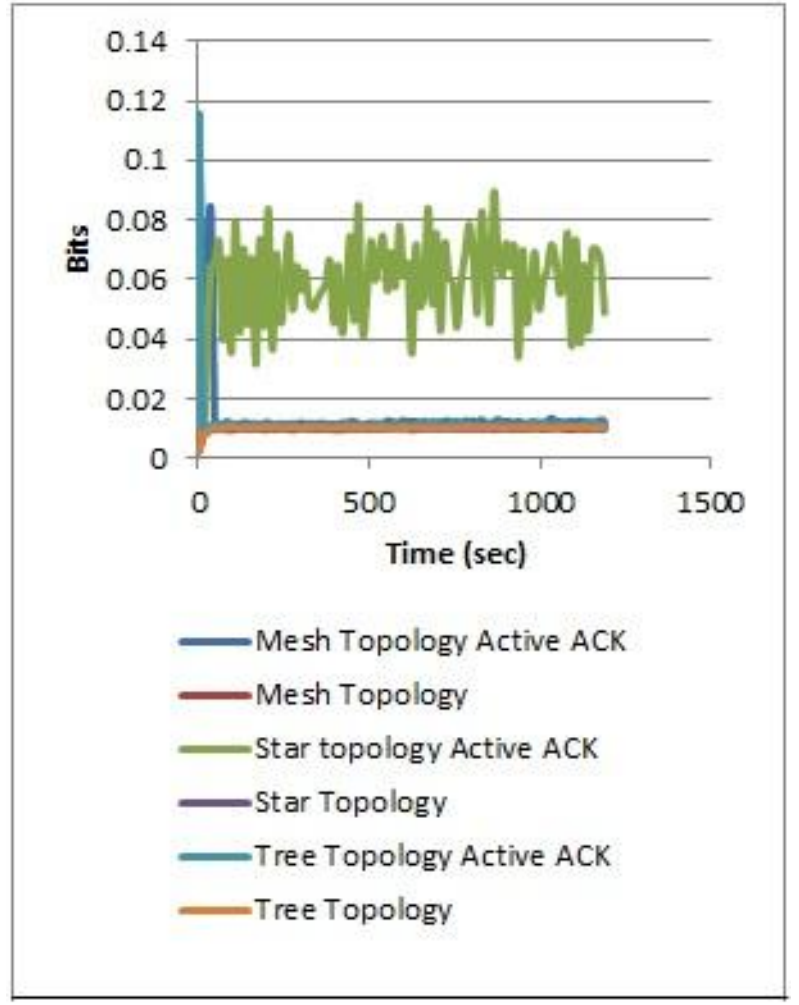

Fig 11: The End to End delay (sec) for the three network topologies before and after activation of ACK

\section{CONCLUSION}

The performance of the Zigbee Tree topology is better than Mesh and star topologies. In the Tree topology the Zigbee devices communicate as hierarchical shape and this regulates the transmission between Zigbee devices. When activation the ACK mechanism the Tree topology was still the best in throughput compare with the other network topology. In contrast, the performance of the star topology decreased significantly, compared to the case of non-activation of ACK mechanism, where the throughput decrease from 22880 bits/sec to 8000 bits/sec and the End to End delay increase from $15 \mathrm{msec}$ to $60 \mathrm{msec}$.

\section{REFERENCES}

[1] Ziang Zhou, Kun $\mathrm{Xu}$ and Dingyun $\mathrm{Wu}$, "Design of Agricultural Internet of Things Monitoring System Based on ZigBee" , CHEMICAL ENGINEERING TRANSACTIONS VOL. 51, 2016.

[2] Thoraya Obaid, HaleemahRashed, Ali Abou-Elnour, Muhammad Rehan, Mussab Muhammad Saleh, and Mohammed Tarique, "ZIGBEE TECHNOLOGY AND ITS APPLICATION IN WIRELESS HOME AUTOMATION SYSTEMS: A SURVEY”, , International Journal of Computer Networks \& Communications (IJCNC) Vol.6, No.4, July 2014.

[3] Salman Naseer and S R Chaudhry, "LR-WPAN Formation Topologies using IEEE 802.15.4" IJCSI International Journal of Computer Science Issues, Vol. 8, Issue 6, No 1, November 2011. 
[4] Dong Zhao, "Dual Coordinator Structure for Zigbee Network", Advanced Materials Research, Vol. 811, pp. 598-601, 2013.

[5] Ms. Sonal J. Rane, "A Simulation Study of Behaviour of Mobile Zigbee Node" , international Journal of Scientific Research Engineering \& Technology (IJSRET) Volume 1 Issue6 pp 001-003 September 2012.

[6] Yi Sun, Yue Sun, Peng $\mathrm{Xu}$ and Haocheng Liu, "Performance Analysis of Wireless Sensor Network Based on OPNET", Communications and Network, 2013, 5, 512-516.

[7] Tien-Wen Sung, Ting-Ting Wu, Chu-Sing Yang, YuehMin Huang, "RELIABLE DATA BROADCAST FOR ZIGBEE WIRELESS SENSOR NETWORKS",
INTERNATIONAL JOURNAL ON SMART SENSING AND INTELLIGENT SYSTEMS, VOL. 3, NO. 3, SEPTEMBER 2010

[8] Anis Koubâa ; André Cunha; Mário Alves; Eduardo Tovar; "TDBS: a time division beacon scheduling mechanism for ZigBee cluster-tree wireless sensor networks" in Real-Time Syst. DOI -10.1007/s11241008-9063-4, Springer Science + Business Media, LLC 2008

[9] Prasad P. Netalkar, Yasha Kaushal and Dr. N. Shekar V. Shet, "Zigbee Based Wireless Sensor Networks for Smart Campus" , International Journal Of Modern Engineering Research (IJMER), Vol. 4 | Iss.7| July. 2014 